\title{
Management of Weber B Ankle Fractures: What have We Learnt since the CROSSBAT Trial?
}

\author{
Sriskandarasa Senthilkumaran ${ }^{1}$, Andrew Oppy ${ }^{2}$, Harvinder Bedi ${ }^{3}$
}

\begin{abstract}
Weber B fractures account for about $50 \%$ of all fractures at the ankle joint. Despite being a common injury, there is clinical equipoise in the management of an isolated lateral malleolar fracture with presumed medial ligamentous injury. The Combined Randomized and Observational Study of Surgery for type B Ankle fracture Treatment (CROSSBAT) study was a multicenter randomized control trial that also had an observational cohort arm. It showed that nonoperative management of Weber B fractures produced equivalent functional results at 1 year and avoided risks and complications that are associated with operative treatment. Other studies have shown similar results in short to mid-term follow-ups. The key to decision-making in ankle fracture is evaluating the stability of the ankle mortice. Weight-bearing radiographs are gaining popularity in this assessment as we understand the important role of the deep deltoid ligament. A lateral malleolar fracture with a medial ligamentous injury that is deemed to be stable by weight-bearing X-rays can be safely managed nonoperatively. Long-term studies are needed to calculate the relative risk of developing post-traumatic arthrosis in these patients compared to those who underwent fixation.

Keywords: Ankle stability, Combined randomized and observational study of surgery for type B ankle fracture treatment, Nonoperative management, Post-traumatic arthrosis, Weber B ankle fracture, Weight-bearing radiograph.

Journal of Foot and Ankle Surgery (Asia Pacific) (2021): 10.5005/jp-journals-10040-1168
\end{abstract}

\section{BACKGROUND}

As with any branch of medicine, orthopedic trauma management has been evolving as we gain more understanding of various fracture patterns and their natural history. Our surgical fixation techniques have improved with significant advances in implant technology. Conversely, it has encouraged surgeons to operate on fractures that otherwise would have previously been managed nonoperatively.

Ankle fractures are the most commonly sustained injuries in 20-65-year-olds with an incidence of 900,000 per year. ${ }^{1}$ About half of these injuries are isolated fractures of the lateral malleolus at the level of the syndesmosis (Weber B) with or without concomitant ligamentous injury. ${ }^{2,3}$ These injuries are also classified as supination external rotation as per the Lauge-Hansen system. Treatment options vary from walker boot to internal fixation. The management decision depends on various factors such as patient comorbidities, fracture pattern, resource availability, and surgeon preference.

Historically, Weber B fractures have been treated with internal fixation, following AO principles. ${ }^{4}$ Integrity of the lateral column of the ankle was thought to be the key to ankle stability. Surgical management ensures the fracture will be anatomically reduced and fixed which in turn, decreases the chance of displacement and malunion. However, surgery is not without its own risks and complication rates of $20 \%$ have been reported in the literature. ${ }^{5}$

There is clinical equipoise with regards to the management of these injuries and there is wide variation in practice among orthopedic trauma surgeons. ${ }^{6,7}$ The combined randomized and observational study of surgery for type $B$ ankle fracture treatment (CROSSBAT) trial $^{8}$ was set up to provide an evidence-based approach to management decision.

\section{CROSSBAT Trial ${ }^{8}$}

This pragmatic trial was carried out by Mittal et al. across 22 centers in Australia and New Zealand in 2010. One hundred and
1Department of Trauma and Orthopaedics, OrthoSport Victoria, Melbourne, Victoria, Australia

${ }^{2}$ Department of Trauma and Orthopaedics, OrthoSport Victoria, Royal Melbourne Hospital; Department of Surgery, University of Melbourne, Melbourne, Victoria, Australia

${ }^{3}$ Department of Trauma and Orthopaedics, OrthoSport Victoria, Box Hill Hospital, Monash University, Melbourne, Victoria, Australia

Corresponding Author: Andrew Oppy, Department of Trauma and Orthopaedics, OrthoSport Victoria, Royal Melbourne Hospital; Department of Surgery, University of Melbourne, Melbourne, Victoria, Australia, e-mail: andrewoppy@me.com

How to cite this article: Senthilkumaran S, Oppy A, Bedi $H$. Management of Weber B Ankle Fractures: What have We Learnt since the CROSSBAT Trial? J Foot Ankle Surg (Asia Pacific) 2021;8(4):158-161.

Source of support: Nil

Conflict of interest: None

sixty patients who had Weber B fractures with minimal talar shift were recruited into the randomized control trial (RCT) arm and 276 patients in the observational arm of the study over 3 years. They were followed up with the American Academy of Orthopaedic Surgeons Foot and Ankle Outcomes Questionnaire (FAOQ) and SF-12v2 General Health Survey at 3, 6, and 12 months.

At the final 12-month follow-up, the nonoperative group had better FAOQ scores which were statistically significant but not relevant clinically. There was no difference in the SF-12v2 scores between the groups. The surgical group was associated with more adverse events. In the short-term, nonoperative treatment provides equivalent results as a surgical outcome. Interestingly, the surgical group in the observational arm of the trial was significantly younger but their scores were less than the non-surgical patients at all points of follow-up.

() The Author(s). 2021 Open Access This article is distributed under the terms of the Creative Commons Attribution 4.0International License (https://creativecommons. org/licenses/by-nc/4.0/), which permits unrestricted use, distribution, and non-commercial reproduction in any medium, provided you give appropriate credit to the original author(s) and the source, provide a link to the Creative Commons license, and indicate if changes were made. The Creative Commons Public Domain Dedication waiver (http://creativecommons.org/publicdomain/zero/1.0/) applies to the data made available in this article, unless otherwise stated. 
It was a well-designed single-blind study with a low rate of cross-over and loss to follow-up. However, the follow-up period was only 1 year, and it can take many years for symptomatic ankle arthrosis to develop.

\section{Systematic Reviews}

A Cochrane review by Donken et al. ${ }^{2}$ in 2012 analyzed 4 RCTs with 292 patients. There was no difference between the surgical and nonsurgical groups; however, it was not possible to pool the data together due to the lack of homogeneity between the trials. The longest follow-up was 7 years. It concluded that there are insufficient data to recommend one treatment over the other.

A systematic review by Julian et al. ${ }^{5}$ in 2020 included 22 studies involving 2523 patients with Weber $B$ ankle fractures. There were 5 RCTs, 4 prospective, and 13 retrospective cohort studies. The follow-up period varied from 6 months to 21 years. Three studies found no difference in the functional scores between the groups. More complications had been reported in the surgical groups as expected. However, one study ${ }^{9}$ reported a delayed radiological union rate of about $20 \%$ at 3 months in the conservatively managed group. The authors did not specify whether it was clinically relevant. This review provides weak evidence that conservative management is equivalent to surgical outcomes but without complications.

\section{Ankle Stability}

The key to decision-making in ankle fracture is evaluating the stability of the ankle mortice. Weber A fractures are proven to be stable and are managed nonoperatively. Weber $C$ fractures are usually managed surgically due to disruption of the syndesmosis. Weber B fractures need close evaluation to identify associated injuries to the distal tibia, deltoid ligament, and syndesmosis ligament complex.

Isolated undisplaced lateral malleolar fractures without any medial injury are inherently stable. Therefore, they should be managed with bracing and early mobilization.

Orthopedic surgeons were traditionally taught that all Weber $B$ fractures with medial or posterior malleolar fractures require internal fixation due to disruption of the bony stabilizers of the ankle mortise. However, the Ankle Injury Management (AIM) trial in 2016 has challenged this belief and has shown that closed contact casting can produce equivalent short-term results for these unstable injuries without the need for internal metalwork in patients over the age of $60 .{ }^{10,11}$ We still await to see the long-term data.

Clinical equipoise arises when a patient presents with isolated lateral malleolar fracture and medial soft tissue injury. It is difficult to quantify the extent of the medial injury clinically or radiologically at the initial presentation. Therefore, an isolated lateral malleolar fracture with presumed medial injury, with any amount of talar shift will be managed surgically by most surgeons.

The role of the deep deltoid ligament in ankle stability has been examined in cadaveric studies and published two decades ago but until recently, it has not been translated into clinical studies. ${ }^{12}$

\section{Imaging}

Surgeons have used various methods to assess the degree of medial soft tissue damage. One procedure is to assess the stability under anesthesia, but it is expensive and not practical in most healthcare systems. Another technique is the use of gravity-assisted stress view, however, it has been shown to overestimate the medial injury and increase the rate of operative intervention. ${ }^{13-16}$

Weight-bearing radiographs are gaining popularity with more evidence being published on their utility in ankle fracture assessment. The radiograph at the initial presentation of the patient is usually taken with the ankle in plantarflexion as it is the most comfortable resting position for patients (Fig. 1). It brings the narrowest part of the talar dome into the profile and the posterior part of the deep deltoid ligament is lax in this position. A combination of these factors shows an artificially increased talar shift. $^{16-18}$

In fractures with an intact deep deltoid ligament, the ankle will be congruent when it is plantigrade (Fig. 2). It is ideal if the weightbearing radiograph is obtained within a few days after the injury once the patient can stand without much pain.

Gougoulias and Sakellariou ${ }^{19}$ reported on their clinical practice which involves weight-bearing radiographs in their fracture clinic. Since the introduction of this system, only $3.7 \%$ of these injuries
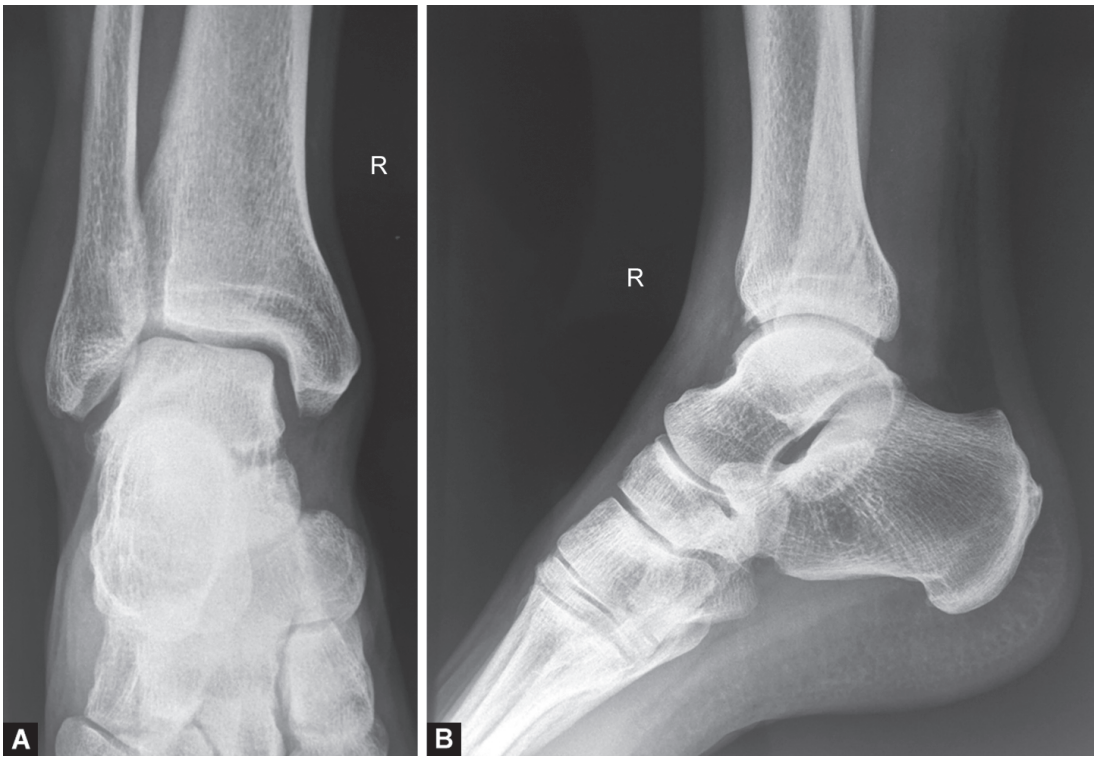

Figs $1 \mathrm{~A}$ and $\mathrm{B}$ : Initial radiograph of a Weber B fracture showing slight medial widening. Note the position of the foot which is in plantar flexion on the lateral view 


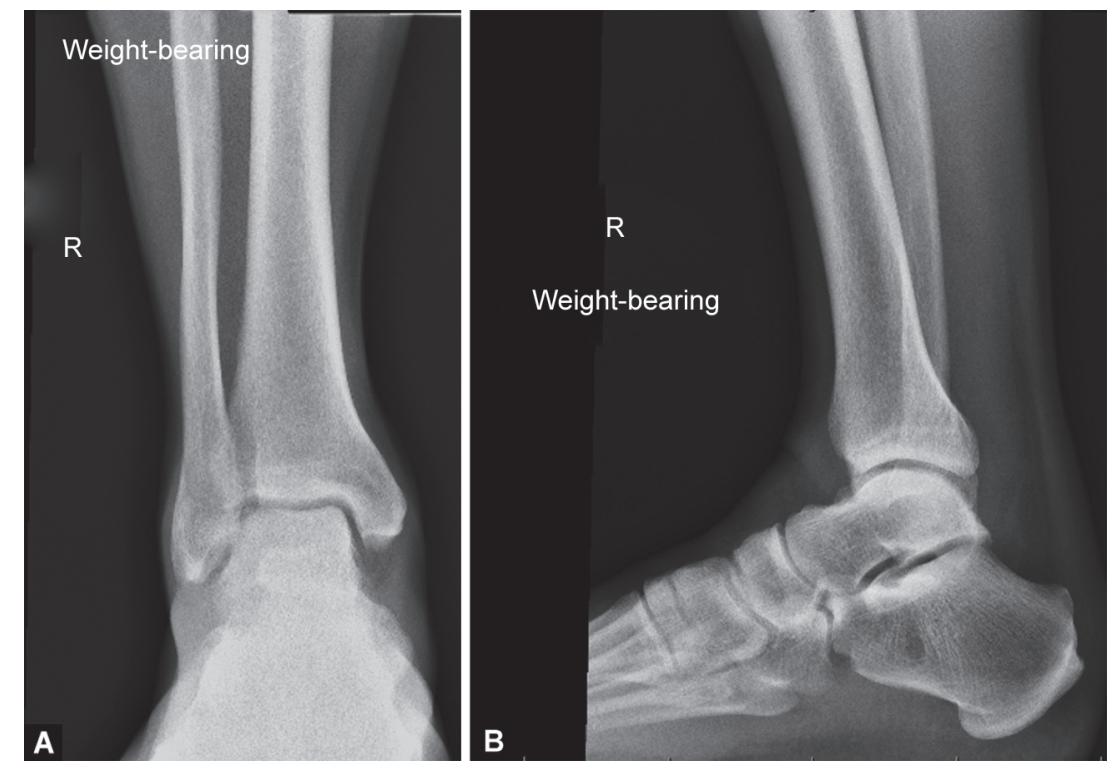

Figs $2 \mathrm{~A}$ and $\mathrm{B}$ : Weight-bearing radiographs at week 1 of the same ankle as Figure 1 shows an anatomically congruent joint

needed internal fixation. None of the conservatively managed fractures needed subsequent fixation.

\section{Post-traumatic Arthrosis}

This is the main concern for surgeons when they manage these injuries nonoperatively. Even though radiological malunion does not necessarily equate to clinical symptoms, surgeons feel uneasy when there is malalignment and feel obliged to operate.

Lübbeke et al. ${ }^{20}$ published a retrospective cohort study with 18 years of follow-up of all ankle fractures who underwent fixation. About $30 \%$ of all Weber B fractures showed advanced arthritic radiographic changes but only half of these patients were symptomatic. Weber $C$ fractures, associated medial malleolar fracture, fracture-dislocation, increasing body mass index, and age of over 30 years were identified as risk factors for symptomatic arthritis. The results were similar to previous short to mid-term follow-up studies on ankle fractures that had been managed surgically. ${ }^{21,22}$

Rooney et al. ${ }^{23}$ presented their results on nonoperatively managed Weber B ankle fractures. Despite the small cohort of 51 patients, there were excellent functional results at 6.8 years. They also showed that a weight-bearing radiograph is a very useful tool in the management of these injuries. There are not many other studies on long-term outcomes of conservatively managed ankle fractures.

\section{Conclusion}

Surgeons should practice by the Hippocratic oath of first do not harm. In Weber B fracture management, stable injuries can be well-managed nonoperatively and avoid exposing them unduly to anesthetic and surgical complications. Stability can generally be assessed well with weight-bearing radiographs although careful follow-up is recommended.

Most surgeons will choose to operate on younger patients to avoid possible future harm, in terms of arthritis. Apart from some small studies, there are not any long-term studies, especially on conservatively managed ankle fractures. A large-scale prospective cohort study is needed to truly understand the natural history of managing these injuries nonoperatively.
It is safe to treat these injuries nonoperatively as long as the patients and their treating surgeons have weighed up the risks and benefits and come to an agreement on the management plan.

\section{References}

1. Dattini R, PatnaikS, Kantak A, et al. Injuries to tibiofibular syndesmosis. J Bone Joint Surg 2008;90-B(4):405-410. DOI: 10.1302/0301620X.90B4.19750.

2. Donken CC, Al-Khateeb $\mathrm{H}$, Verhofstad MH, et al. Surgical versus conservative interventions for treating ankle fractures in adults. Cochrane Database Syst Rev 2012(8):CD008470. DOI: 10.1002/14651858.CD008470.pub2.

3. Weber BG. Die Verletzungen Des Oberen Sprung-Gelenkes. 2nd ed., Berne: Verlag Hans Huber; 1972.

4. Müller ME, Allgöwer M, Schneider R, et al. Manual of internal fixation: techniques recommended by the AO group. 2 nd ed., Ch. 14, Berlin: Springer-Verlag; 1979. pp. 595-612.

5. Larsen P, Rathleff MS, Elsoe R. Surgical versus conservative treatment for ankle fractures in adults - a systematic review and meta-analysis of the benefits and harms. Foot Ankle Surg 2019;25(4):409-417. DOI: 10.1016/j.fas.2018.02.009.

6. Julian TH, Broadbent RH, Ward AE. Surgical vs non-surgical management of Weber B fractures: a systematic review. Foot Ankle Surg 2020;26(5):494-502. DOI: 10.1016/j.fas.2019. 06.006 .

7. Lin CW, Donkers NA, Refshauge KM, et al. Rehabilitation for ankle fractures in adults. Cochrane Database Syst Rev 2012;11:CD005595. DOI: 10.1002/14651858.CD005595.pub3.

8. Mittal R, Harris IA, Adie $S$, et al. Surgery for type B ankle fracture treatment: a combined randomised and observational study (CROSSBAT). BMJ Open 2017;7(3):e013298. DOI: 10.1136/bmjopen2016-013298.

9. Sanders DW, Tieszer C, Corbett B. Canadian orthopedic trauma society. Operative versus nonoperative treatment of unstable lateral malleolar fractures: a randomized multicenter trial. J Orthop Trauma 2012;26(3):129-134. DOI: 10.1097/BOT.0b013e3182460837.

10. Willett $K$, Keene DJ, Mistry D, et al. Close contact casting vs surgery for initial treatment of unstable ankle fractures in older adults: a randomized clinical trial. JAMA 2016;316(14):1455-1463. DOI: 10.1001/ jama.2016.14719.

11. Keene DJ, Lamb SE, Mistry D, et al. Three-year follow-up of a trial of close contact casting vs surgery for initial treatment of unstable 
ankle fractures in older adults. JAMA 2018;319(12):1274. DOI: 10.1001/ jama.2018.0811.

12. Michelson JD, Ahn UM, Helgemo SL, et al. Motion of the ankle in a simulated supination-external rotation fracture model. JBJS 1996;78A(7):1024-1031. DOI: 10.2106/00004623-199607000-00006.

13. Gill JB, Risko T, Raducan V, et al. Comparison of manual and gravity stress radiographs for the evaluation of supination-external rotation fibular fractures. J Bone Joint Surg Am 2007;89(5):994-999. DOI: 10.2106/JBJS.F.01002.

14. Seidel A, Krause F, Weber M. Weight bearing vs gravity stress radiographs for stability evaluation of supination-external rotation fractures of the ankle. Foot Ankle Int 2017;38(7):736-744. DOI: 10.1177/1071100717702589.

15. Hastie GR, Akhtar S, Butt U, et al. Weight bearing radiographs facilitate functional treatment of ankle fractures of uncertain stability. J Foot Ankle Surg 2015;54(6):1042-1046. DOI: 10.1053/j.jfas.2015.04.025.

16. Dawe EJ, Shafafy R, Quayle J, et al. The effect of different methods of stability assessment on fixation rate and complications in supination external rotation (SER) 2/4 ankle fractures. Foot Ankle Surg 2015;21(2):86-90. DOI: 10.1016/j.fas.2014.09.010.

17. Weber $M$, Burmeister $H$, Flueckiger $G$, et al. The use of weight bearing radiographs to assess the stability of supination-external rotation fractures of the ankle. Arch Orthop Trauma Surg 2010;130(5):693-698 DOI: 10.1007/s00402-010-1051-1.

18. Lampridis V, Gougoulias N, Sakellariou A. Stability in ankle fractures: diagnosis and treatment. EFORT Open Rev 2018;3(5):294-303. DOI: 10.1302/2058-5241.3.170057.

19. Gougoulias N, Sakellariou A. When is a simple fracture of the lateral malleolus not so simple? How to assess stability, which ones to fix and the role of the deltoid ligament. Bone Joint J 2017;99-B(7):851-855. DOI: 10.1302/0301-620X.99B7.BJJ-2016-1087.R1.

20. Lübbeke A, Salvo D, Stern R, et al. Risk factors for post-traumatic osteoarthritis of the ankle: an eighteen year follow-up study. Int Orthop 2012;36(7):1403-1410. DOI: 10.1007/s00264-011-1472-7.

21. Müller J, Plaass U, Willenegger HII. Spätergebnisse nach operativ behandelten malleolar frakturen [Late results after surgically treated malleolar fractures. II]. Helv Chir Acta 1971;38(3):329-337.

22. Beris $A E$, Kabbani $K T$, Xenakis $T A$, et al. Surgical treatment of malleolar fractures. A review of 144 patients. Clin Orthop Relat Res 1997(341):90-98. DOI: 10.1097/00003086-19970800000015.

23. Rooney EM, Finney FT, Talusan P, et al. Mid term 5-year follow up of a novel algorithm for non-operative Weber B ankle fractures. Foot Ankle Orthop 2019(5). DOI: 10.1177/2473011419S00366. 